\title{
Accuracy Analysis of ADS-B System In a Training Airport
}

\author{
Youhui Zhang ${ }^{1, a}$, Liang Zhao,b \\ ${ }^{1}$ Civil Aviation Flight University of China, Guanghan, China \\ acafuczyh@163.com \\ b30375838@qq.com
}

\begin{abstract}
ADS-B is a new type of ATC system based on GNSS. As the aircraft in the route is a 3D target, the $3 \mathrm{D}$ coordinates of the location information is very important, positioning accuracy directly affects the ADS-B system reliability and efficiency. In this paper, various error models are established, and the Positioning effect of ADS-B static and dynamic targets are analyzed. The simulation results can only reflect the errors of ADS-B to some extent. In addition, the simulation does not take into account the delay of UAT data chain. The errors in the delay time, especially in the course direction, are bigger than the simulation result, which can be eliminated or weakened by the method of track prediction. Elevation information is calculated from the barometric altimeter in the real system with greater error.
\end{abstract}

Keywords: GPS, Klobuchar model, Magnavox model, GDOP

\section{Introduction}

Global Positioning System (GPS) is a Global Navigation Satellite System (GNSS) ${ }^{[1]}$. The system has been widely used in life. If you want to meet global coverage, you requires 24 satellites whose orbit at 20,000 km altitude. But in order to ensure system performance, and now the number of satellites remained about 30. The minimum requirements of the 24 satellites, the official called "Core Constellation". With the progress of the GPS modernization program, civilian signals will include L1 C/A (carrier 1575.42MHz), L2C (carrier $1227.6 \mathrm{MHz}$ ), L5 (1176.45MHz) and L1C (carrier $1575.42 \mathrm{MHz}$ ). The basic principle of GPS positioning is to establish the relationship between the time and distance of the satellite to the receiver, taking into account the error between the satellite clock and the receiver clock, the pseudo range equations in the $3 \mathrm{D}$ frame of axes ${ }^{[2]}$, such as Eq.1:

$$
\rho=\mathrm{c}\left(\mathrm{t}_{\mathrm{s}}-\mathrm{t}_{\mathrm{r}}\right)=\sqrt{\left(\mathrm{x}-\mathrm{x}_{\mathrm{n}}\right)^{2}+\left(\mathrm{y}-\mathrm{y}_{\mathrm{n}}\right)^{2}+\left(\mathrm{z}-\mathrm{z}_{\mathrm{n}}\right)^{2}}+\mathrm{c} \Delta \tau
$$

$\rho$ is the satellite-to-receiver pseudo range, $c$ is the speed of light, $t_{s}$ is the satellite clock, $t_{r}$ is the receiver clock, The coordinates of the receiver $(\mathrm{x}, \mathrm{y}, \mathrm{z})$ and the satellite coordinates $\left(\mathrm{x}_{\mathrm{n}}, \mathrm{y}_{\mathrm{n}}, \mathrm{z}_{\mathrm{n}}\right)$. But $t_{r}$ is not accurate, the deviation from the exact value is $\Delta \tau$.

Beidou2 (BD2) is China's independent research and development of the global satellite navigation system. Although there are differences in the constellation distribution and navigation messages from GPS, the positioning principle is very similar to GPS. Future system will consist of 35 satellites, consisting of 27 medium earth orbit satellites (MEO), 3 inclined geosynchronous orbit satellites (IGSO) and 5geostationary equatorial orbit satellites (GEO). The signals are B1 (carrier 1561.098 MHz), B2 (carrier 1207.140 MHz), B3 (carrier 1268.520 MHz). According to the official website, as of June 2016, the system has launched 23 satellites in orbit ${ }^{[3]}$. 
In recent years, the demand for GNSS in the aviation field is getting higher. The International Civil Aviation Organization (ICAO) and Civil Aviation of China (CAAC) are actively promoting the new navigation technology - Performance Based Navigation (PBN), which is used for route navigation and approach, Satellite Landing System (GLS) for entry and departure, Automatic Dependent Surveillance-Broadcast (ADS-B) for aircraft surveillance.

\section{ADS-B system}

The simple structure of ADS-B is shown in Fig.1.The airborne receiver determines its own position by the positioning information of the satellite broadcast. The encoder encapsulates the solution into an ADS-B message format and forwards it to the ground station. The ground station receives the message and the satellite signal at the same time, and then processes the data through the network to the user and determines its position. Thus, the user can monitor the dynamic position of the aircraft and the ground station coordinates. At present, the airport is using the $978 \mathrm{MHz}$ UAT data $\operatorname{link}^{[4]}$.

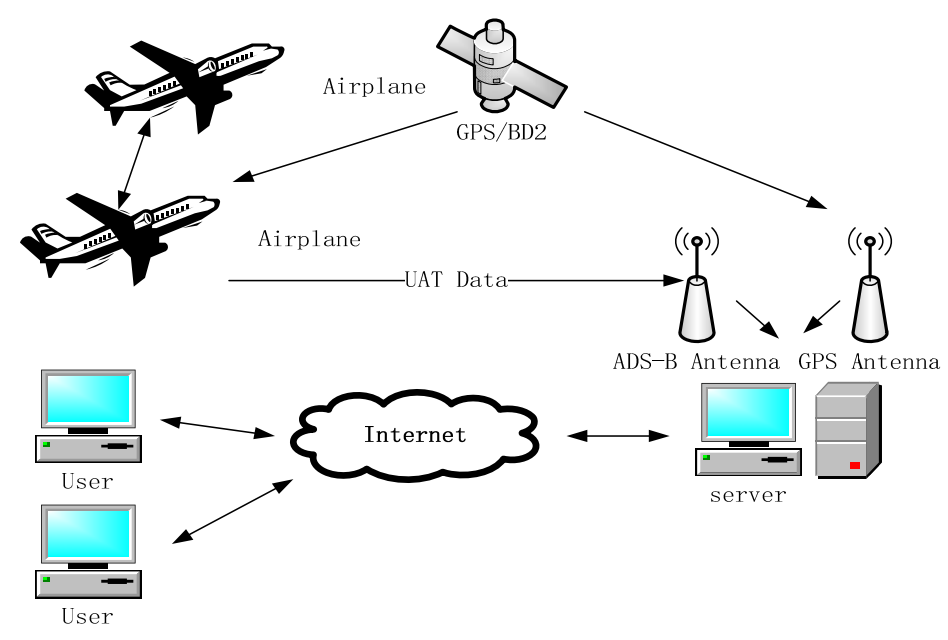

Fig.1 Schematic diagram of ADS-B system

\section{Error analysis and model establishment}

From Figure 1, the errors of the system are mainly caused by satellite positioning errors and data update delay. The ground station is relatively static and its error sources are satellite clock, ephemeris, ionospheric delay model, tropospheric delay and multipath effect, which need to be reduced or eliminated in the simulation. Eq.1 of the pseudo range equations are rewritten as:

$$
\rho=\sqrt{\left(\mathrm{x}-\mathrm{x}_{\mathrm{s}}\right)^{2}+\left(\mathrm{y}-\mathrm{y}_{\mathrm{s}}\right)^{2}+\left(\mathrm{z}-\mathrm{z}_{\mathrm{s}}\right)^{2}}+\mathrm{c} \Delta \tau+\mathrm{c} \Delta \mathrm{t}+\mathrm{E}+\mathrm{T}_{1}+\mathrm{T}_{2}+\mathrm{M}+\mathrm{n}
$$

$\mathrm{E}$ is the ephemeris error, $\mathrm{T}_{1}$ and $\mathrm{T}_{2}$ are the ionosphere and troposphere delay, $\mathrm{M}$ is the multipath effect, $\mathrm{n}$ is the noise of receiver. For the calculation of the aircraft, due to the limitation of the frame length of UAT, the delay of $1 \mathrm{~s}$ is increased on the basis of the Eq.2.

Clock Error Model: Satellites use stable atomic clocks, but still have frequency offsets and aging rates, the positioning system time base will be biased. So, the mathematical expression of the satellite clock such as Eq.3:

$$
\Delta \tau(\mathrm{t})=\mathrm{a}_{0}+\mathrm{a}_{1}\left(\mathrm{t}-\mathrm{t}_{0}\right)+\mathrm{a}_{2}\left(\mathrm{t}-\mathrm{t}_{0}\right)^{2}
$$

$\mathrm{a}_{0}$ is the satellite clock zero bias correction parameters, $\mathrm{a}_{1}$ is clock speed corrected parameter, $\mathrm{a}_{2}$ is clock speed rate corrected parameter, $t_{0}$ is clock corrected reference time. These parameters are broadcast in the navigation message. In the interface control document of GPS and BD2 ${ }^{[5]}$, the relative modification: 
$\Delta \mathrm{t}_{\mathrm{r}}=\mathrm{Fe}_{\mathrm{s}} \sqrt{\mathrm{A}} \sin \mathrm{E}_{\mathrm{k}}$

$\mathrm{e}_{\mathrm{s}}$ is the orbital eccentricity, $\mathrm{A}$ is the Orbital semi-major axis, $\mathrm{E}_{\mathrm{k}}$ is the eccentric anomaly, $\mathrm{F}$ is the constant.

$$
\begin{gathered}
\mathrm{F}_{\mathrm{GPS}}=-4.4428076334 \times 10^{-10} \mathrm{~s} / \mathrm{m}^{1 / 2} \\
\mathrm{~F}_{\mathrm{BD} 2}=-4.4428073090 \times 10^{-10} \mathrm{~s} / \mathrm{m}^{1 / 2}
\end{gathered}
$$

In addition, these parameters are broadcast in the navigation message. The group delay correction $\mathrm{T}$ is also given. The result:

$\delta \mathrm{t}=\Delta \tau(\mathrm{t})+\Delta \mathrm{t}_{\mathrm{r}}+\mathrm{T}$

ionospheric delay model: Due to ionization, the propagation velocity of electromagnetic waves are affected. At present, the ionospheric delay is the main error term for GPS and BD2 systems. The ionospheric model is divided into theoretical model and empirical model, such as IRI model, Bent model, CRI model, VTEC model, spherical harmonic model, WAAS and Klobuchar model ${ }^{[6]}$. Klobuchar model is widely used in single frequency GPS receiver system. For the L1 band single-frequency receiver, the expression is Eq.4:

$$
\mathrm{T}= \begin{cases}\mathrm{D}+\mathrm{A} \cos \left(\frac{2 \pi\left(\mathrm{t}-\mathrm{T}_{\mathrm{P}}\right)}{\mathrm{P}}\right) & \text { DAY TIME } \\ \mathrm{D} & \text { NIGNT TIME }\end{cases}
$$

$\mathrm{D}=5 \mathrm{~ns}, \mathrm{~T}_{\mathrm{P}}=50400 \mathrm{~s}, \mathrm{~A}$ is the cosine curve amplitude, $\mathrm{P}$ is the cosine curve period. The satellite provides eight ionospheric parameters $\left(\alpha_{1}, \alpha_{2}, \alpha_{3}, \alpha_{4}, \beta_{1}, \beta_{2}, \beta_{3}, \beta_{4}\right)$, which are used to calculate $\mathrm{A}$ and $\mathrm{P}$.

$$
A=\left\{\begin{array}{ll}
\sum_{i=0}^{3} \alpha_{i}\left(\varphi_{m}\right)^{i} & A \geq 0 \\
0 & A<0
\end{array} \quad P= \begin{cases}\sum_{i=0}^{3} \beta_{i}\left(\varphi_{m}\right)^{i} & P \geq 72000 \\
72000 & P<72000\end{cases}\right.
$$

The calculation process requires five known quantities: satellite elevation angle, satellite azimuth, receiver longitude and latitude of the receiver at WGS-84 coordinates, GPS system time. The calculation process is not described in detail here.

Tropospheric delay ${ }^{[7]}$ model: There is no relation between the troposphere delay and signal frequency. Generally, there are Chao model, Hopefield model, Magnavox model, Collins model, Saastamoinen model and so on. The latter three models do not need to establish a relationship with meteorological data, the use of more convenient, Magnavox model such as Eq.5:

$$
\Delta \mathrm{D}=\frac{2.208}{\operatorname{sinE}}\left(\mathrm{e}^{\mathrm{h}_{\mathrm{r}} /-6900}-\mathrm{e}^{\mathrm{h}_{\mathrm{s}} /-6900}\right)
$$

$\mathrm{h}_{\mathrm{r}}$ is the receiver height, $\mathrm{h}_{\mathrm{s}}$ is the satellite altitude, $\mathrm{E}$ is the satellite elevation.

Multipath effect: The ground station location is generally more open, in order to simplify the calculation, no longer considered. For dynamic aircraft, the multipath performance is also dynamically changed randomly, similar to white noise processing. However, it should be noted that the system has a 1s delay. Small aircraft cruising speed in the absence of other factors is about $200 \mathrm{Km} / \mathrm{h}$, the aircraft's error $=$ the error of the last second + the current error $+1 \mathrm{~s}$ at the moment the flight distance. 


\section{Case studies}

Firstly, the satellite constellation is built according to the satellite orbit parameters ${ }^{[8]}$. Figure 2 shows the track of sub-satellite point and coverage of 32 GPS and 30 BD2 in the same 24 hours. BD2 has better coverage in the Asia-Pacific region:

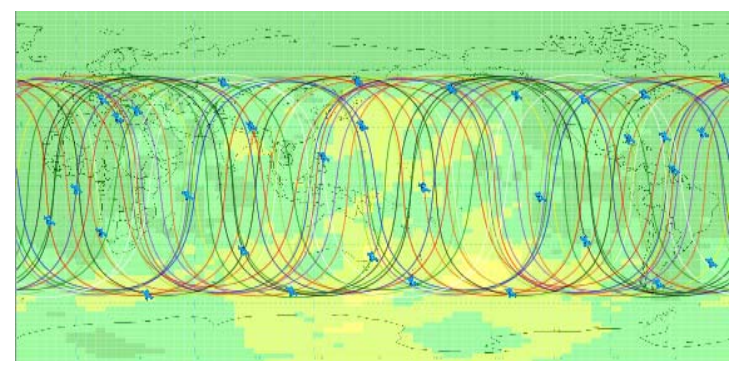

Fig.2 (a) The track of sub-satellite point and coverage of GPS

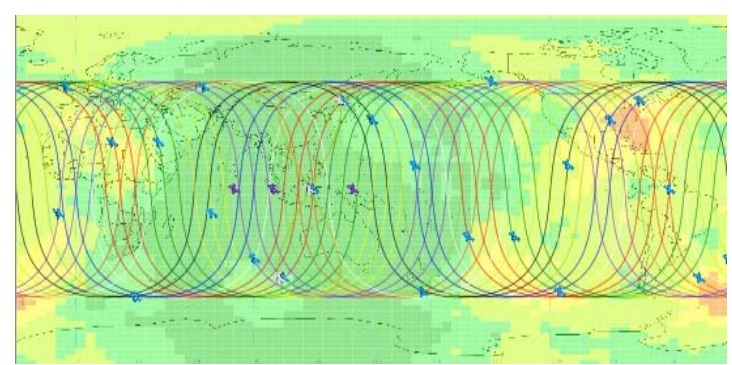

(b) The track of sub-satellite point and coverage of BD2

The latitude and longitude of the airport is about B30.95 L104.32 H467.57 in the geodetic coordinate system. Assuming a single frequency receiver (L1 or B1) ground station in this position, it takes into account the above errors and selects the elevation is greater than or equal to 5 degrees of satellite shown in figure 3, (X, Y, Z) is the spatial Cartesian coordinate system of the CGCS2000 (with a very small deviation from WGS 84), the abscissa is the sampling step, the unit is Minute and the ordinate is $\mathrm{m}$ :
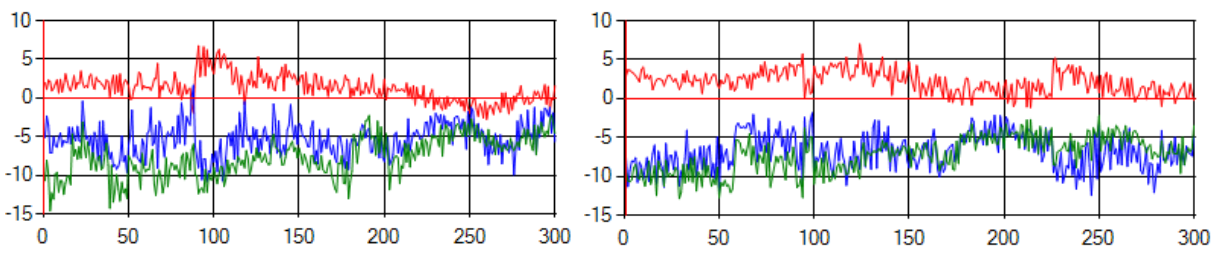

Fig.3 GPS and BD2 positioning errors

The average positioning error of GPS and BD2 receiver is about $10 \mathrm{~m}$. After eliminating the effects of ionospheric error, tropospheric error and multipath effect, the localization results are shown in Fig. 4:
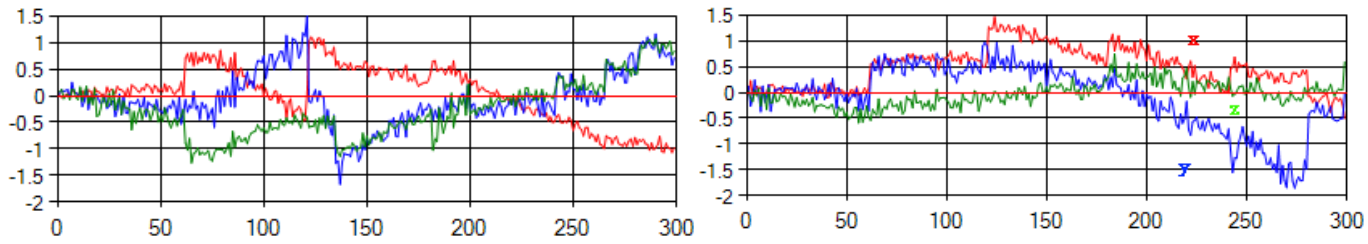

Fig. 4 GPS and BD2 positioning results after error elimination

Several routes of the airport were established to study the effect of the dynamic model. Route coordinates as shown in Figure 5, the aircraft flight altitude of $2000 \mathrm{~m}$, speed $200 \mathrm{~km} / \mathrm{h}$, no landing flight:

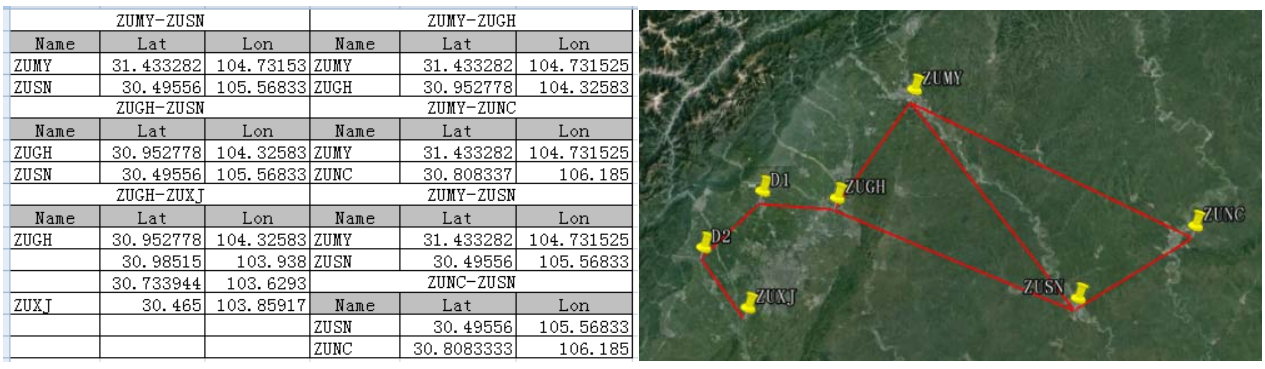

Fig.5 Coordinates and routes 
As shown in Fig. 6, in the ZUGH-ZUXJ sector, the precision is represented by the geometrical dilution of precision(GDOP). GPS system errors $=$ DOP $\times$ user pseudo range errors:

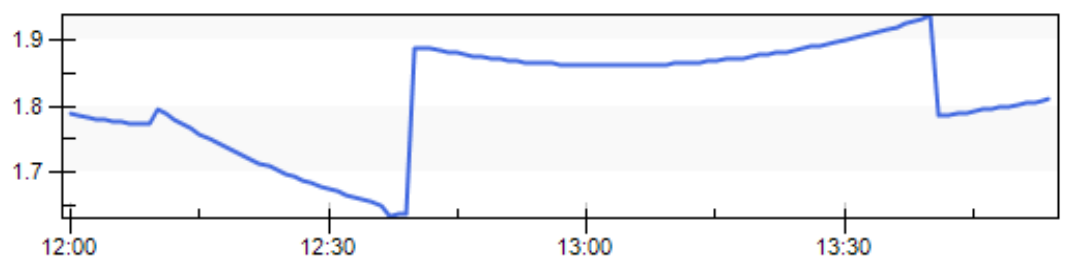

Fig.6 GDOP of the ZUGH-ZUXJ segment

As shown in Figure 7, GDOP of the system in the ZUGH-ZUMY-ZUNC-ZUSN segment:

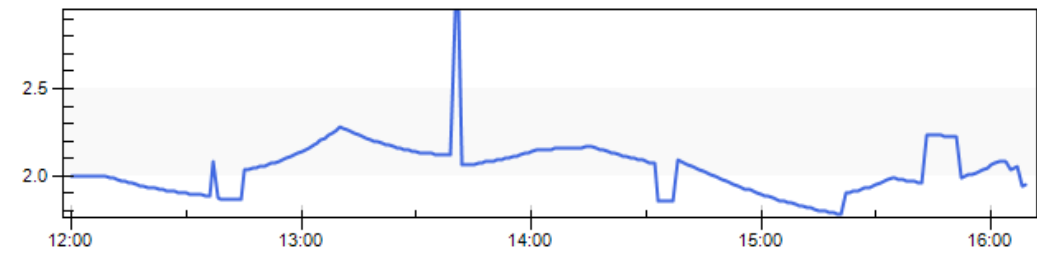

Fig.7 GDOP of the ZUGH-ZUMY-ZUNC-ZUSN segment

BD2 is similar and will not be described in detail. From the above analysis, we can see that, after eliminating most of the errors, the user error has been very small, so the ADS-B error is not large, mainly related to the GDOP value. It should be noted that the actual situation is more complex. The simulation results can only reflect the errors of ADS-B to some extent. In addition, the simulation does not take into account the delay of UAT data chain. The errors in the delay time, especially in the course direction, are bigger than the simulation result, which can be eliminated or weakened by the method of track prediction. Elevation information is calculated from the barometric altimeter in the real system with greater error.

\section{References}

[1] Ji Longzhe, Shan Qingxiao, The Development Outline and Latest Evolution of Global Navigation Satellite system, J. GNSS WORLD OF CHINA. Vol.37, No.5 October,2012. p56-61

[2] FEI bao-jun, SUN wei-jun, The Relativity Correction for GPS Pseudo-range Equation, J. Journal of Institute of Surveying and Mapping. Vol.21, No.3 Sept.2004. p169-171

[3] Information on http:// http://www.beidou.gov.cn/

[4] LI Desheng, The Design and Implementation of ADS-B Airborne System Based on UAT Data link, J. Aviation Maintenance \& Engineering.2012/2.p56-58

[5] GPS interface control document \& BD interface control document

[6] R Filjar, TKS Kos. Klobuchar-Like Local Model of Quiet Space Weather GPS Ionospheric Delay for Northern Adriatic, J. Journal of Navigation, 2009, 62(3):p543-554

[7] Kos, T Markežić, I Botinčan, Maja. Evaluation of Different Tropospheric Delay Models,J. Gnss Vulnerabilities \& Solutions Conference, 2008

[8] YU Yanting. STK software and Its Application in Satellite Navigation Systems, J. Ship Electronic Engineering. Vol,36 No.7,2016.p62-65 